\section{TROUBLE AT THE TOP}

When it comes to high-quality research, the United States has no equal. It contributes a third of the authorship in the Nature Index, churning out almost as many papers as China, Germany and the United Kingdom combined. But there are signs of change in the global research arena.

The total number and global share of articles from the US has decreased since 2012, when the index began tracking high-quality research. The country's contribution to paper authorship has also declined at a faster pace, in absolute and relative terms.

This downward trend in high-quality research is reflected in the larger Web of Science (WoS) database. Between 2005 and 2015, the US share of highly cited papers fell faster than its share of total articles indexed in the WoS.

The research trajectory of the US is almost the reverse of China's, where publication numbers and author contribution have surged since 2012. If the current rate of change continues, China could be the top contributor to paper authorship in the index by 2027.

Almost every state has played a role in the country's decline in authorship. Reduced contributions from California, Massachusetts, New York and Maryland have made the biggest dent in weighted fractional count (WFC) over the past five years. However, five states have increased their contribution by a few points.

Analysts Scott Andes and Daniel Correa see the overall US decline as an inevitable by-product of a financially constrained research community, as they outline in a commentary (S13). Federal spending on research and development as a percentage of GDP has been receding since the 1960 s. Barring an influx of funds, science and the economy will continue to suffer.

But publication numbers are only one instrument for diagnosing the health of a country's research ecosystem, as Julia Lane points out in her commentary (S14). US investment in alternative tools of analysis will lead to more efficient spending on science, and will invigorate the economy,

Lane argues.

DATA ANALYSIS BY AARON BALLAGH, BO WU AND DAVID PENDLEBURY (CLARIVATE ANALYTICS)
DROP IN HIGH-QUALITY OUTPUT

The contribution of the United States to the high-quality journals included in the Nature Index has declined in absolute and relative terms. Its share of authorship (WFC) has declined at a slightly faster rate than its share of articles (AC).
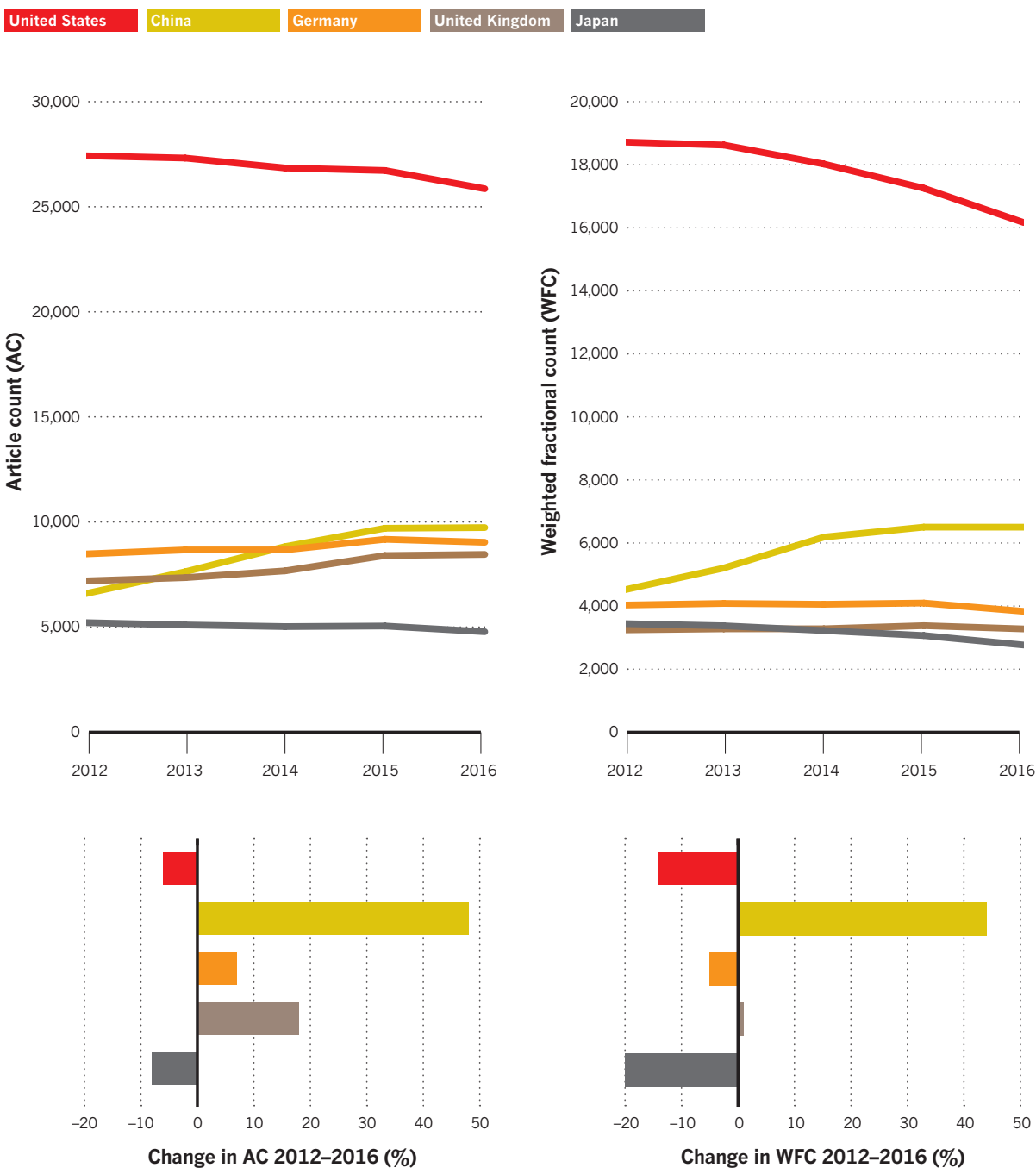

LOWER SHARE OF TOTAL OUTPUT

The United States' share of highly cited papers has decreased at a faster rate than its share of total articles indexed in the Web of Science (WoS) between 2005 and 2015.

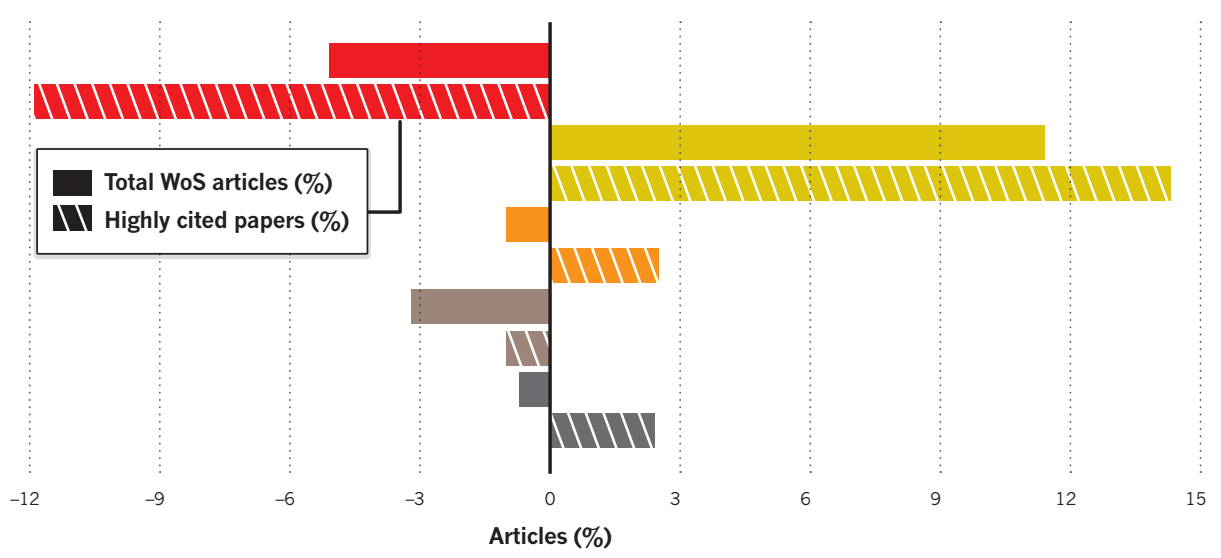


STATE PERFORMANCE

California (CA 3,067.3), on the west coast, contributes the most in weighted fractional count (WFC) to the share of authorship in the Nature Index in 2016, followed by several states on the east coast: Massachusetts (MA 1,656.7), New York (NY 1,453.4) and Maryland (MD 798).

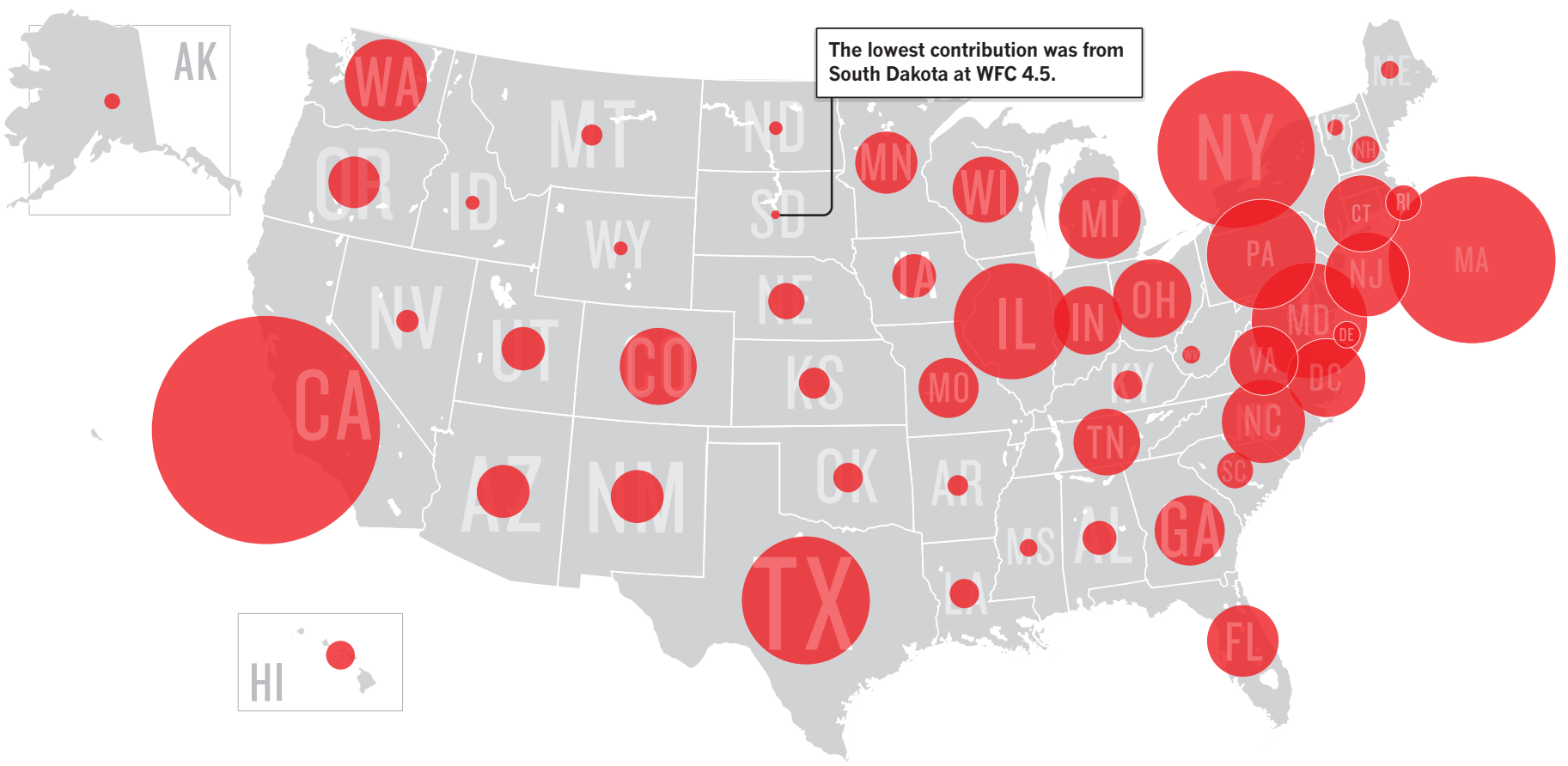

The majority of states have seen a decline in their contribution to the Nature Index between 2012 and 2016 . This graph shows the percentage change of each state's WFC between 2012 and 2016.

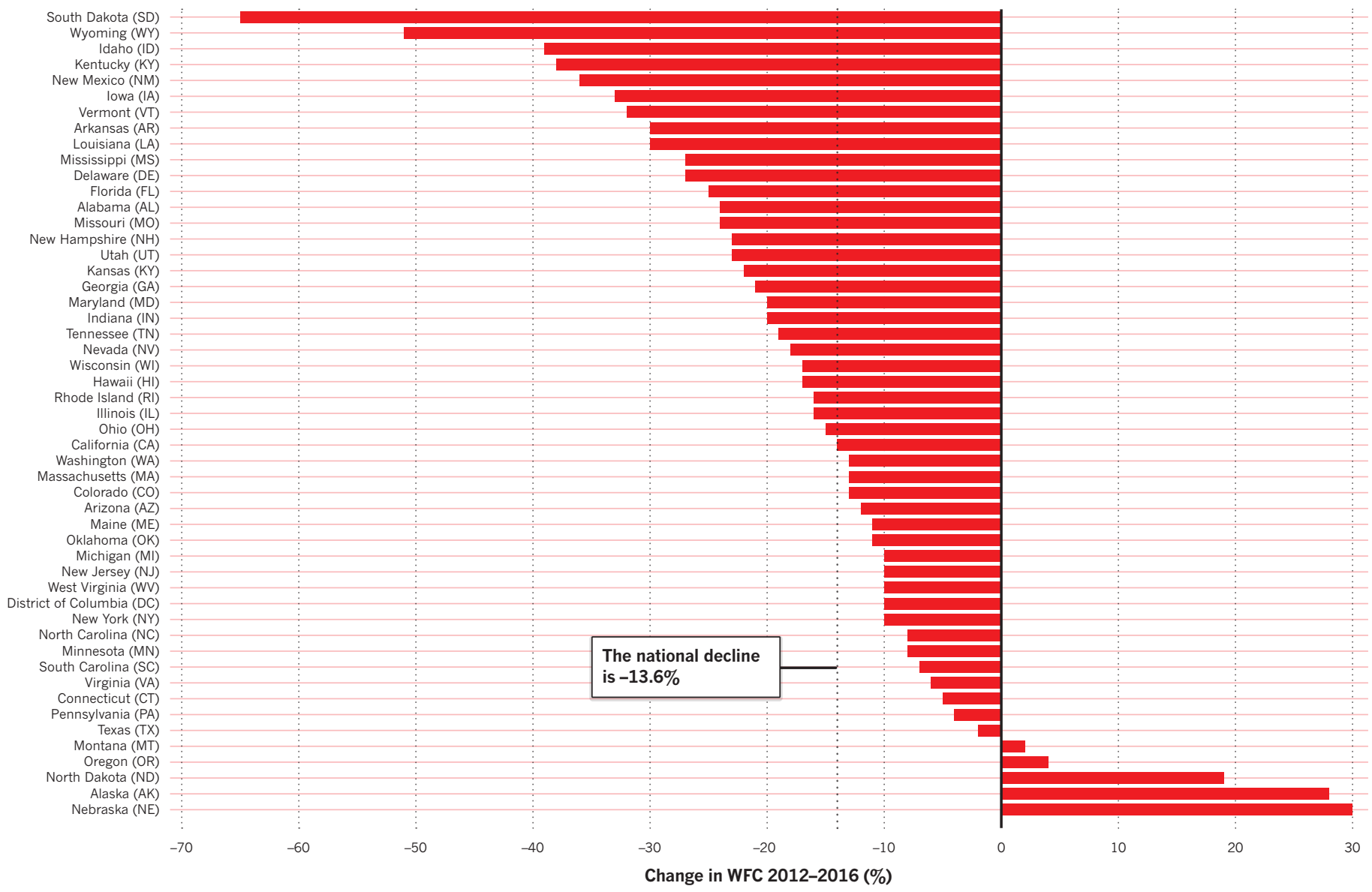

